\title{
The choice of anesthetic agent does not predict the occurrence of postoperative delirium in cardiac surgery: A prospective observational study
}

\section{Background and goal of the study}

Postoperative delirium (PD) in cardiac surgery patients is a major problem and results in increased morbidity. Studies have suggested that a sevoflurane-based anesthesia was better associated with short-term cognitive function than propofol. ${ }^{1}$ We sought whether the choice of the anesthetic agent could influence the incidence of PD in a cohort of patients undergoing all types of cardiac surgery with or without cardiopulmonary bypass.

\begin{abstract}
Material and methods
This is a sub-analysis of a large prospective observational trial evaluating the neurologic outcome of adult patients undergoing cardiac surgery (NCT 02006212). A total of 1500 patients will be included for the purposes of the study. In all patients cerebral oxygen saturation $\left(\mathrm{ScO}_{2}\right)$ is measured before the induction of anesthesia. Subjects are evaluated for PD during the entire hospital stay. At the ward, the evaluation is performed every 4 to 6 hours. No standard screening tests are used. However, signs and symptoms of hypoactive, hyperactive and mixed delirium are actively searched.

Data are expressed in median (P25-P75) or numbers and percentages. A Mann-Whitney and Chi square tests are used to compare respectively continuous and dichotomous variables between both groups. A binary regression analysis was performed to predict PD. The type and the total dose of anesthetic agents were considered as independent variables. $\mathrm{P}<0,05$ is considered significant.
\end{abstract}

\section{Results and discussion}

In total 620 patients were analyzed. PD occurred in $20 \%$ of the patients.

Table 1: Characteristics and data of patients with or without PD

Table 2: Predictive factors of PD

\begin{tabular}{|c|c|c|c|c|c|c|c|}
\hline & $P D(N=126)$ & No PD (N=494) & $\mathbf{P}$ & Variables & $P$ value & Odds Ratio & $95 \% \mathrm{Cl}$ for OR \\
\hline Age (Years) & $74(64-80)$ & $67(57-75)$ & $<0,001$ & Mean baseline ScO2 & 0,309 & 0,989 & $0,967-1,011$ \\
\hline EuroSCORE II & $\begin{array}{c}1,93 \\
(1,08-3,64)\end{array}$ & $\begin{array}{c}1,67 \\
(0,94-3,13)\end{array}$ & 0,013 & Sevoflurane & 0,691 & 0,911 & $0,576-1,441$ \\
\hline Male/female & $84 / 42$ & $353 / 141$ & 0,383 & Dose ketamine/weight & 0,228 & 0,443 & $0,118-1,665$ \\
\hline n baseline $\mathrm{ScO} 2(\%)$ & $61(56-67)$ & $63(56-69)$ & 0,013 & Dose midazolam/weight & 0,339 & 151 & $0,0005-4434973$ \\
\hline$t$ baseline ScO2 (\%) & $60(54-66)$ & $62(56-69)$ & 0,046 & Surgery on left sided cavities & 0,855 & 1,042 & $0,668-1,628$ \\
\hline t baseline ScO2 (\%) & $60(56-67)$ & $64(56-69)$ & 0,008 & $\underline{\text { Age }}$ & $\underline{0,000}$ & $\underline{1,039}$ & $\underline{1,021-1,058}$ \\
\hline $\begin{array}{l}\text { Irgery on left sided } \\
\text { cavities }\end{array}$ & 87 (69\%) & $321(65 \%)$ & 0,54 & EuroSCORE II & 0,485 & 1,021 & $0,962-1,084$ \\
\hline Sevoflurane & $84(67 \%)$ & $322(65 \%)$ & 0,84 & & & & \\
\hline Midazolam & $121(96 \%)$ & $477(97 \%)$ & 0,04 & \multirow{3}{*}{\multicolumn{4}{|c|}{$\begin{array}{l}\text { The Hosmer and Lemeshow test showed a chi-square } \\
\text { statistic of } 6,855 \text { with } P=0,552 \text {. }\end{array}$}} \\
\hline $\begin{array}{l}\text { dose midazolam per } \\
\text { weight }(\mathrm{mg} / \mathrm{kg})\end{array}$ & $\begin{array}{c}0,048(0,033- \\
0,060)\end{array}$ & $\begin{array}{c}0,048(0,034- \\
0,058)\end{array}$ & 0,82 & & & & \\
\hline Ketamine & $106(84 \%)$ & $443(65 \%)$ & 0,01 & & & & \\
\hline
\end{tabular}
Total dose Ketamine per
0,36 weight $(\mathrm{mg} / \mathrm{kg})$
$(0,24-0,48)$
0,38
$(0,26-0,47)$
0,55

Data are expressed in median ( Percentile 25 - Percentile 75)

\section{Conclusions}

This is the first large prospective study evaluating the impact of the anesthetic regimen on the incidence of PD. Our preliminary results show that

1. The choice of the anesthetic agent does not influence the incidence of PD in cardiac surgery patients.

2. Age remains the only independent predictor of PD.

\section{References}

